San Jose State University

SJSU ScholarWorks

Master's Theses

Master's Theses and Graduate Research

1990

\title{
The influence of adapted physical education exercise classes on the self-concept of the post-stroke student
}

Mary F. Bennett

San Jose State University

Follow this and additional works at: https://scholarworks.sjsu.edu/etd_theses

\section{Recommended Citation}

Bennett, Mary F., "The influence of adapted physical education exercise classes on the self-concept of the post-stroke student" (1990). Master's Theses. 3304.

DOI: https://doi.org/10.31979/etd.xern-5k46

https://scholarworks.sjsu.edu/etd_theses/3304

This Thesis is brought to you for free and open access by the Master's Theses and Graduate Research at SJSU ScholarWorks. It has been accepted for inclusion in Master's Theses by an authorized administrator of SJSU ScholarWorks. For more information, please contact scholarworks@sjsu.edu. 


\section{INFORMATION TO USERS}

The most advanced technology has been used to photograph and reproduce this manuscript from the microfilm master. UMI films the text directly from the original or copy submitted. Thus, some thesis and dissertation copies are in typewriter face, while others may be from any type of computer printer.

The quality of this reproduction is dependent upon the quality of the copy submitted. Broken or indistinct print, colored or poor quality illustrations and photographs, print bleedthrough, substandard margins, and improper alignment can adversely affect reproduction.

In the unlikely event that the author did not send UMI a complete manuscript and there are missing pages, these will be noted. Also, if unauthorized copyright material had to be removed, a note will indicate the deletion.

Oversize materials (e.g., maps, drawings, charts) are reproduced by sectioning the original, beginning at the upper left-hand corner and continuing from left to right in equal sections with small overlaps. Each original is also photographed in one exposure and is included in reduced form at the back of the book.

Photographs included in the original manuscript have been reproduced xerographically in this copy. Higher quality 6" $\times 9$ " black and white photographic prints are available for any photographs or illustrations appearing in this copy for an additional charge. Contact UMI directly to order.

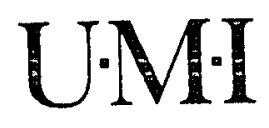



Order Number 1341655

The influence of adapted physical education exercise classes on the self-concept of the post-stroke student

Bennett, Mary Frances, M.A.

San Jose State University, 1990 

The Influence of Adapted Physical Education Exercise Classes on the Self-Concept of the Post-stroke Student

\author{
A Thesis \\ Presented to \\ The Department of Human Performance \\ San Jose State University
}

In Partial Fulfillment

of the Requirements for the Degree

Masters of Arts

By

Mary F. Bennett

August, 1990 
APPROVED FOR THE DEPARTMENT OF HUMAN PERFORMANCE

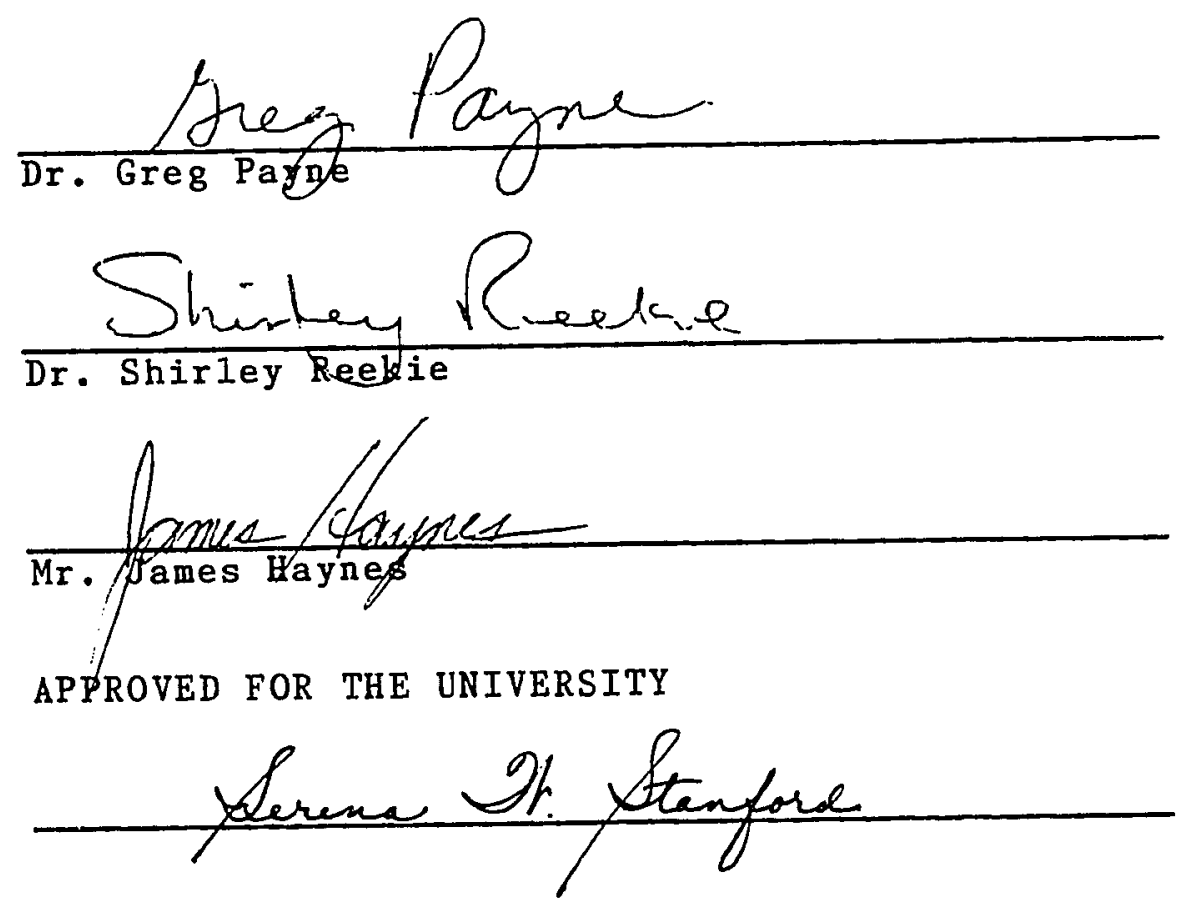




\section{Acknowledgements}

I would like to express many thanks to the members of my committee, Dr. Greg Payne, Dr. Shirley Reekie, and Mr. James Haynes, for their professional guidance and assistance during the completion of this thesis.

Dedication of this work goes to my husband, Brian J. Bennett and my parents, Randolph $K$. and Esther M. Zell, for all the love and patience in completing this thesis.

A special thank you goes to Henderson Ford for all his valued time and expertise. 
Table of Contents

Page

Acknowledgement $\ldots \ldots \ldots \ldots \ldots \ldots \ldots \ldots \ldots \ldots \ldots \ldots$ i $\ldots \ldots \ldots$

List of Tables .......................... vi

Abstract $\ldots \ldots \ldots \ldots \ldots \ldots \ldots \ldots \ldots \ldots \ldots \ldots \ldots \ldots$ vii

Chapter

1. Introduction $\ldots \ldots \ldots \ldots \ldots \ldots \ldots \ldots \ldots \ldots \ldots \ldots \ldots$

Purpose of the Study .............. 3

Research Hypotheses .............. 3

Delimitations ................. 5

Limitations .................... 5

Operational Definition of Terms ....... 6

Summary $\ldots \ldots \ldots \ldots \ldots \ldots \ldots \ldots \ldots \ldots \ldots \ldots$

2. Review of Literature ................. 8

Se1f-Concept .................. 9

Sensation $\ldots \ldots \ldots \ldots \ldots \ldots \ldots \ldots$

Cognition ..................... 9

Reinforcement Dependence ......... 10

Physical Self ................. 11

Intellectual Self .............. 11

Moral-Ethical self ............. 11

Emotional Self ................ 12

Social Self .................. 12

Self-Concept and the 01der Adult ...... 12 


$$
\begin{aligned}
& \text { Self-Concept and Stroke ............ } 15 \\
& \text { Self-Concept and Physical Performance ... } 17 \\
& \text {. Physical Performance ............... } 19
\end{aligned}
$$

3. Procedures ......................... 25

subjects ..................... 25

Description of the Instrument ....... 26

Research Design ................. 27

Research Hypothesis ............... 28

Statistical Procedures ............ 30

Summary ......................... 30

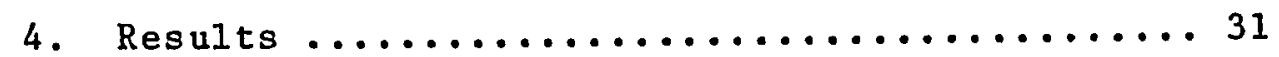

Results .......................... 31

Discussion ............................. 39

5. Summary, Conclusions, ard Recommendations ... 45

summary ...................... 45

Conclusions ................... 45

Recommendations ................ 46

Reference List .......................... 48

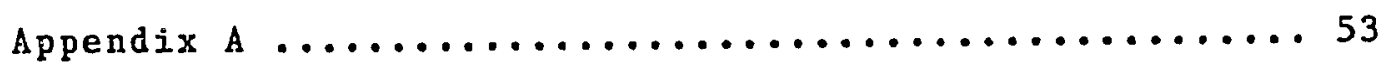




\section{List of Tables}

Table

Page

1. Analysis of Variance for Total Self Score by

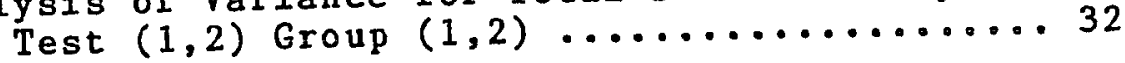

2. Analysis of Variance for Physical Self by Test $(1,2)$ Group $(1,2) \ldots \ldots \ldots \ldots \ldots \ldots \ldots \ldots$

3. Analysis of Variance for Moral-Ethical Self by Test $(1,2)$ Group $(1,2) \ldots \ldots \ldots \ldots \ldots \ldots \ldots . \ldots 34$

4. Analysis of Variance for Personal Self by Test $(1,2)$ Group $(1,2) \ldots \ldots \ldots \ldots \ldots \ldots \ldots \ldots$

5. Analysis of Variance for Family Self by

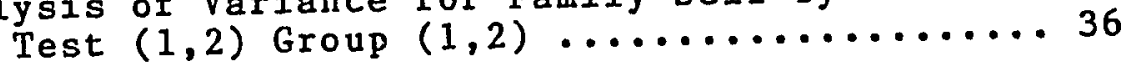

6. Analysis of Variance for Social Self by Test $(1,2)$ Group $(1,2) \ldots \ldots \ldots \ldots \ldots \ldots \ldots \ldots$

7. Analysis of Variance For Self-Criticism by Test $(1,2)$ Group $(1,2) \ldots \ldots \ldots \ldots \ldots \ldots \ldots$ 


\section{ABSTRACT}

THE INFLUENCE OF ADAPTED PHYSICAL EDUCATION EXERCISE CLASSES ON THE SELF-CONCEPT OF THE POST-STROKE STUDENT

$$
\text { by Mary F. Bennett }
$$

This study investigated the effect of adapted physical education on the pre-test and post-test self-concept scores of the 29 post-stroke students enrolled in adapted physical education classes at De Anza College. These scores were compared to the scores of seven post-stroke students enrolled in the Reach Program at Foothill College who acted as the control group. All of the subjects ranged between the ages of 45 and 80 years.

The Tennessee Self-Concept Scale (Fitts, 1964) was administered to both the experimental and control group before and after the 12-week 1990 Winter Quarter. An analysis of variance was used to analyze the pre-test and post-test scores of the experimental and control groups. No significant difference was found between the self-concept scores of the experimental and control groups. On the basis of this study, adapted physical education classes do not appear to have an effect on the self-concept of the post-stroke student. 
Chapter I

Introduction

An individual's attitudes and behavior are consistent with his/her self-concepts. "Self-concept, defined as an individual's perception of himself, is an important psychological construct that influences one's attiaudes and behavior" (Brinkmann \& Hoskins, 1979, p. 859). Self-concept reflects the valuation of self, goal setting, and the attainment of one's potential. "Any experience or situation that causes a person to question or decrease the value placed on self causes a decline in self-soncept" (Taft, 1985, p. 79).

Specific disabilities may affect an elderly person's self-concept. Stroke is a major cause of disability in the elderly (Marsh, 1984). The most prevalent functional disabilities following a stroke include vocational activity, socialization, interest in hobbies, and participation in household tasks (Robinson, Bolduc, Kubol, Starr \& Price, 1985). These functional disabilities can be adversely affected by the person's psychological state. Other factors affecting the post-stroke student include impairment of intellectual reasoning, memory loss, and disturbances in speech. The disability may also result in a diminished self-concept (Robinson et al., 1985). Stroke patients have a tendency to believe that others 
think less of them then before and will avoid them because of their disabilities (Aitken, 1982). A stroke victim must often develop a new self-concept. The individual's achievements prior to the stroke (business, personal, and social), and his/her self-concept, are diminished because of the disabilities due to the stroke. Opportunities for positive attitude development and behavior changes will be needed to reconstruct the stroke victim's self-concept.

Research has shown that as individuals increase physical fitness, behavior associated with an improved self-concept was also demonstrated (Beekman, Axtej.1, Noland \& West, 1985; Brinkmann \& Hoskins, 1979; Collingwood \& Willett, 1971; Collingwood, 1972). Physical therapists often observe improvements in clients' appearance and socialization as clients become more physically able (Short, DiCarlo, Steffee, \& Pavlou, 1984). Self-concept has been observed to improve following exercise programs for various groups of subjects (Brinkmann \& Hoskins, 1979).

Recognizing that behavior and attitudes improve as a result of exercise programs, this evaluation has potential to provide a better understanding about the self-concept of the post-stroke sidudent. A Detter understanding may serve as a basis for more effective teaching methods and curriculum design and will increase the pool of professional information about the post-stroke student. 
Purpose of the Study

The purpose of this study was to measure the influence of adapted physical education exercise classes on "an individual's perception of himself" (Brinkmann \& Hoskins, 1979, p. 859), using post-stroke subjects. Whether the self-concept scores changed from the pre-test to the post-test was determined and the significance of these scores was noted.

\section{Research Hypotheses}

The hypotheses for this study were tested at the .008 level of acceptance (adjusted from .05 due to multiple use of ANOVA's).

1. There will be no difference between the pre-test self-concept rankings and the post-test self-concept rankings for post-stroke students enrolled in adapted physical education exercise classes at De Anza College.

2. There will be no difference between the pre-test self-concept rankings and the post-test self-concept rankings regarding the experimental group and the control group.

3. There will be no difference between the pre-test self-concept rankings and post-test self-concept rankings regarding the Physical Self dimension of the Tennessee SelfConcept Scale. 
4. There will be no difference between the pre-test self-concept rankings and post-test self-concept rankings regarding the Moral-Ethical Self dimension of the Tennessee Self-Concept Scale.

5. There will be no difference between the pre-test selí-concept rankings and post-test self-concept rankings regarding the Personal Self dimension of the Tennessee SelfConcept Scale.

6. There will be no difference between the pre-test self-concept rankings and post-test self-concept rankings regarding the Family Self dimension of the Tennessee SelfConcept Scale.

7. There will be no difference between the pre-test self-concept rankings and post-test self-concept rankings regarding the Social Self dimension of the Tennessee SelfConcept Scale.

8. There will be no difference between the pre-test self-concept rankings and post-test self-concept rankings regarding the Self-Criticism Score of the Tennessee SelfConcept Scale.

9. There will be no difference between the pre-test self-concept rankings and post-test self-concept rankings regarding the Total Self Score of the Tennessee Self-Concept Scale. 
Delimitations

This study was delimited to the mile and female adult post-stroke students enrolled in adapted physical education classes during the 1990 Winter Quarter offered at De Anza College and the Reach Program at Foothill College. This study was also delimited to the use of the Tennessee Self-Concept Scale.

\section{Limitations}

The Iimitations of this study were the following:

1. The sample size may not be an adequate representation of the population of male and female poststroke individuals.

2. Subjects may not have responded to test items candidly and may have withheld responses due to the personal nature of the questions.

3. Generelizations from this study were limited to the participants of the study and may not be indicative of all post-stroke subjects.

4. This study was limited to the use of only one self-concept scale.

5. The subjects used for this study were from only one geographical area.

6. The study was limited to the return of the Tennessee Self-Concept Scale under the proposed guidelines and on-time. 
7. This study was limited to the individualized adapted physical education program for each subject.

8. This study was limited to the use of one control group. The control group may have been in a situation to improve their self-concept.

\section{Operational Definition of Terms}

The definitions used for this study were the following:

1. Stroke. Stroke is defined as the sudden onset of a focal neurological deficit due to presumed local disturbances in the blood supply to the brain (Dombovy, Burton, Sandrok \& Basford, 1986).

2. Adapted physical education. A modified weight training program individually designed to maintain or improve strength and flexibility of the post-stroke student. The student participates in this program three times per week for one hour, each day. The intensity of the exercise is individual for each student.

3. Hemiplegia. Paralysis occuring to only one half of the body (Thomas, 1981).

4. Student. For the purpose of this study, a student will be defined as one who is enrolled three hours a week in an adapted physical education exercise class at De Anza Col1ege.

5. Enrolled. A student who is legally registered at De Anza College, does not miss more than nine hours of 
instruction during the Winter, 1990 quarter, and fulfills the course requirements.

Summary

This study determined whether or not a class in adapted physical education affects the self-concept of the post-stroke student. The results of this study may enable the educator to better understand the self-concept of the subject and may also serve as a basis for a more effective teaching and research design. 


\section{Chapter II}

\section{Review of Literature}

For the purposes of this review, the literature has been divided into five categories: (1) 1iterature defining self-concept; (2) literature pertaining to self-concept and the aged; (3) literature pertaining to self-concept and post-stroke individuals; (4) 1iterature pertaining to selfconcept and physical performance and (5) literature pertaining to the Tennessee Self-Concept Scale.

"Self-concept, or the way in which an individual sees himself, is a primary directional factor in the individual's personality and is instrumental in determining the individual's level of adjustment" (Gaber, 1984, p. 207). A positive attitude about one's self leads to high levels of personality adjustment, whereas a negative attitude imposes limitations upon the person's behavior and level of adjustment (Gaber, 1984). Brinkmann and Hoskins (1979) revealed that a high evaluation of self results in goal setting and attempts to reach those goals. A low evaluation of self results in reinforcement of feelings of a devalued self. "In order to preserve his devalued self-concept, a person may limit the success that he will allow himself" (Brinkmann \& Hoskins, 1979, p. 859). 


\section{Self-Concept}

Self-concept is a significant factor in the individual's behavior. The conceptual process is valuable to the person in problem solving, survival, communication, and in trying to reduce anxiety. The process by which one develops selfconcept is defined by Gergen (1971). He divides the development of self-concept into three parts: (I) sensation; (2) cognition; and (3) reinforcement dependence.

\section{Sengation}

Gergen defines the sensation stage of self-concept development as "the individual's experience of raw data" (Gergen, 1971, p. 25). During this stage, the individual begins to increase his sensitivity to the perceived differences in the stimuli.

\section{Cognition}

During the cognition stage, the individual begins to group the stimuli in a multitude of ways. "As a result of interactions with the environment, cognitive structures evolve" (Tesser \& Campbell, 1983, p. 2). The cognitive stage is characteristic of an ontogenetic-cognitive appoach to self-concept according to Tesser and Campbell (1983). During this phase, the individual becomes capable of both registering and grouping sensations. 
Reinforcement Dependence

While the sensation and cognition stages of the development of self-concept relate to tendencies towards categorization, the functional value of self-concepts are dependent on reinforcement from the environment (Gergen, 1971). Reinforcement is the reason we select one self-concept over another in any particular instance. Reinforcement can be derived from reward and/or punishment. This may cause the person to develop a new self-concept if the punishment and pain persist.

Schwarzer (1984) recognized that "self-concept can be conceived of as the total of self-reverent information which an individual has processed, stored, and organized in a systematic manner" (p. 1). He defines self-concept as a "set of organized knowledge about oneself" (Schwarzer, 1984, p. 1). Schwarzer cites a study by Shavelson and Marsh (1984) in which they subdivide self-concept into three categories which they believe play a role in developing an image of oneself. The three categories are (1) academic, (2) social and emotional, and (3) physical.

Shavelson and Marsh (1984) believe that the academic category of developing one's self-concept is the most important. The academic self-concept is formed "by evaluative feedback about one's performance from family, friends and teachers" (Schwarzer, 1984, p. 1). From this 
evaluation, the person can monitor his accomplishments and failures with regards to the social, emotional, and physical categories of developing one's own self-concept. The person can use the evaluation about his performance by comparing himself to others with regards to "social norms" set by that particular society.

Driever (1976) defines self-concept as "the composite of beliefs and feelings that one holds about oneself at a given time, formed from perceptions, particularly of other's reactions, and directing one's behavior" (Driever, p. 169). He divides self-concept into five components: (1) physical self, (2) intellectual self, (3) moral-ethical self,

(4) emotional self and (5) social self.

\section{Physical Self}

The physical self "encompasses the body's structure, function, and appearance as well as dimensions such as sexuality and wellness-illness state" (Driever, 1976, p. 170).

\section{Intellectual Self}

The intellectual self includes rational and cognitive abilities. Memory and creative capabilities are encompassed in the intellectual self.

\section{Moral-Ethical Self}

The moral-ethical self includes a person's conscience. This component of a person's self-concept is responsible for setting standards for the individual to live by. 
Emotional Self

The emotional self is composed of a person's feelings and emotions. The emotional self is also composed of a person's drive to better himself in society.

\section{Social Self}

Driever (1976) believes that the social self is subject to what others think of us. How we interact with others in society is encompassed in the social self.

Taft (1985) states that "value is placed on each component of self-concept that then determines the satisfaction or dissatisfaction individuals experience with that aspect of their self-concept" (p. 78).

Gaber (1984) includes in his study a definition of self-concept. He defines self-concept "as the way an individual sees himself" (p. 207). Gaber (1984) concludes that "self-concept is a primary directional factor in the individual's personality and is instrumental in determining the individual's level of adjustment" (p. 207).

Self-Concept and the 01der Adult

Lewis (1984) estimates that by the year 2030, 20-30 percent of the United States population will be over the age of 65. Aitken (1992) predicts by the year 2000, 16 percent of the total population will be over the age of 65 . Over 75 percent of those over 65 years of age suffer from chronic conditions such as heart conditions, arthritis and 
visual impairments (Lewis, 1984). Since these chronic conditions often depict illness and weakness, older persons are alienated from other generations. Beverley (1975) reports that "as long as we believe that old people are poor, isolated, sick, and unhappy, we are able to separate ourselves comfortably from older persons and relegate them to inferior status" (p. 117).

$$
\text { According to Taft (1985) older people are, as a group, }
$$

looked upon as a risk for a lowered self-concept. This is because they suffer diminished work and social roles, and are vulnerable to grief from loss of family members and friends (Taft, 1985). Bloom (1961) believes that the quality of physical, social, economic, and psychological experiences decline with age. "Any experience or situation that causes a person to question or decrease the value placed on self causes a decline in self-concept" (Taft, 1985, p. 79).

"The most significant factor in determining emotional adjustment in old age is the person's perception of himself as old and his assumption of the role of an old person" (B10om, 1961, p. 534). "The aged person's perception of his world and of himself may be a more critical determinant of his adjustment to actual facts of what his world is or how or what he is" (Preston \& Gudiksen, 1966, p. 63).

Brody, Kleban, Lawton and Silverman (1971) believe that "in our society, the elderly are at a higher risk than 
younger populations with respect to mental and physical health, income, interpersonal losses and losses of status, roles and occupation" (Brody et al., p. 124). Guptiii (1969) observed that men who identified themselves as being old had a more negative self-concept than those who identified themselves as being young.

Since there is a decline in physical health in the clder adult, denial is a common factor. "The persistence of denial of physical deterioration in the elderly may be because of their need to believe that they have some control over their 1ife" (Aitken, 1982, p. 245). Denial of physical illness can be achieved by individuals viewing themselves as younger because physical illness occurs only in those who are old (Aitken, 1982). Preston and Gudiksen (1966) interviewed 120 subjects over 65 years of age. During the interviews, the subjects freely verbalized their attitudes about their current and past lives. From these interviews, a 110 item true-false questionnaire was constructed and administered to 242 subjects over 65. Preston and Gudiksen found that the high scores recorded for the questionnaire were due to denial. They concluded that these scores "represent a prevailing tendency among subjects to rely on mechanisms of denial when reporting their conditions (Preston \& Gudiksen, 1966, p. 67).

Denial was suggested by Aitken (1982) as a means for 
older individuals to insulate themselves from societal devaluation. Puglisi and Jackson (1978) studied older adults from nursing homes and retirement homes using the Tennessee Self-Concept Scale. They found that subjects who identified themselves as young, middle-aged had a higher self-concept than those who indentified themselves as old.

\section{Self-Concept and Stroke}

Stroke is the third leading cause of death in the United States (Dombovy et al., 1986). Most survivors of stroke are left with mental and physical disabilities such às hemiparesis, dysphasia, and impairment of memory. "Out of every 100 survivors of the acute phase of stroke, 10 will return to work without disability, 40 will have mild disability, 40 will be severly disabled and 10 will require institutionalization" (Dombovy et al., 1986, p. 363).

Stroke victims frequently sustain a severe psycnosocial disability, which can be a major detriment in the rehabilitation process (Labi, Phillips \& Gresham, 1980). Stroke patients tend to display a negative attitude about their self-worth and believe that others will feel uneasy towards them, because of their disability. They fear "their invalidism or chronic debilitating illness might lead to depending upon society for survival" (Aitken, 1982, p. 245). Stroke victims are more likely to avoid resuming their social relationships because of the perceived stigma of 
stroke. Hyman (1971) studied 200 stroke patients using the Kenny Self-Care Evaluation Scale. The subjects used for this study were participating in a stroke rehabilitation program. Hyman reported that feelings of loneliness and lack of dependable relatives and friends exerted adverse effects on motivation. The data showed that when patients exhibited an aversion to resuming social participation at the beginning of the program, motivation, and functional improvements were not seen during the program. He concludes that these feelings of stigma "constitute a potentially strategic point of intervention for attempts to improve the results of rehabilitation" (Hyman, 1971, p. 140).

In another study examining a similar phenomenon, Lipsey and Robinson (1987) state that "following stroke, the patient may be unable to resume his previous occupation and fear becoming a burden to his family. He may be disfigured by his illness and worry that others will be unable to accept his altered appearance" (p. 57). Lipsey, Robinson, Godfrey, Pearson, Rao and Price (1985) studied stroke patients for several years and found "between 30 percent and 60 percent of both acute and chronic stroke patients have clinically significant depressions" ( $p$. 59). They found that the high risk period for depression lasted for about two years.

A re-evaluation of the self-concept "is necessary for 
the setting of high-level goals and the attainment of one's potential" (Brinkmann \& Hoskins, 1979, p. 859). Stroke victims must accept themselves before they can obtain maximum benefit from a rehabilitation program.

\section{Self-Concept and Physical Performance}

Self-concept has been shown to improve following exercise programs for various subjects. Physical therapists often observe improvements in clients' appearances and socialization as clients become more physically able and independent. Short, DiCarlo, Steffee, and Pavlou (1984) studied 45 obese men using the Tennessee Self-Concept Scale. They found that aerobic conditioning is associated with an improved self-concept. Brinkmann and Hoskins (1979) studied the effect of a physical conditioning program on the measure of self-concept in hemiplegic patients using both the TSCS and the Social Vocabulary Index. They found that significant improvements in self-concept occured after the physical conditioning program.

In a similar study involving self-concept and physical performance, Beekman et al. (1985) reported that as a result of participation in a four-week rehabilitation program, 81 patients with chronic low back pain demonstrated significant positive changes in self-concept. The self-concept scale used for this study was the Tennessee Self-Concept Scale. 
Collingwood and Willett (1971) studied the effects of physical training on self-concept using the TSCS. Five obese male teenagers participated in a three week physical training program. The authors reported a significant increase in self-concept as physical fitness performance increased. Collingwood and Willet concluded that the experience gave the subjects "Fositive feedback of themselves" (Collingwood \& Willet, p. 412) which improved their self-concept.

Collingwood (1972) assessed the effects of physical training on the the self-concept of 50 subjects using the Body Attitude Scale of the Osgoods Semantic Differential Scale. A control group and an experimental group were used for this study. Twenty-five young males (age 18-26) participated in a four week physical training program. The control group, also with 25 young males, did not participate in a physical training program. At the conclusion of the physical training program, Collingwood found $50 \%$ of the experimental grcup demonstrated a positive change in selfconcept. The control group demonstrated only a $30 \%$ positive attitude change. Collingwood concluded that the data support the contention that gains in physical training can result in greater self-concept improvement than without physical training.

In a similar study, Heinzelmann and Bagley (1970) 
studied the effects of an 18 month physical activity program on the self-concept of 239 obese males (age 45-59 years). The subjects were asked questions about their self-image before and after the physical activity program. Data was gathered on the subjects' attitudes, beliefs, and behavior. They found that physical activity helped improve the subject's self-image. The subject's improved self-image was demonstrated by more favorable attitudes, beliefs, and behavior towards work and diet.

Morgan, Roberts, Brand and Feinerman (1970) studied 67 male subjects ranging in age from 26-55 years. The subjects participated in a six-week exercise program. The Zung Self Rating Depression Scale (SDS) was filled out prior to and after the six-week exercise program. The researchers found that "depressed males can experience a significant reduction in depression following six weeks of chronic exercise" (Morgen et al., p.217).

\section{Physical Performance}

The American College of Sports Medicine has developed guidelines for exercise prescription. They recommend:

1. Frequency of training : 3-5 days per week.

2. Intensity of training: $60-90 \%$ of maximum heart rate.

3. Duration of training: 20-60 minutes of continuous aerobic activity (American College of Sports Medicine, $1990, p=265)$. 
The 1990 position paper of the American College of Sports Medicine (replacing the 1978 position paper) concludes that, although 15 to 20 weeks is a guideline for experimental research regarding the aging, "more inquiry into the relationship of long-term training (quantity and quality), for both competitors and non-competitors, and physiological function with increasing age is necessary before more definitive statements can be made" (American College of Sports Medicine, 1990, p. 268).

\section{The Tennessee Self-Concept Scale}

The need for a scale which was "simple for the subject, widely applicable, well standardized, and multi-dimensional in its description of the self-concept" (Fitts, 1964, p. 1) prompted the development of the Tennessee Self-Concept Scale (TSCS). The original purpose of the TSCS "was to develop a research instrument that might contribute to the difficult criterion probiem in mental health" (Fitts, 1964 , p. 1). Seven separate dimensions of health are measured by the TSCS. Physical Self, Moral-Ethical Self, Personal Self, Family Self, and Social Self assess the subject's perceptions of his or her behavior. In addition, the Self-Criticism Score measures the derogatory comments about oneself. The seventh dimension is the Total Self Score, which is a composite of the subject's overall level of self-esteem. 
The TSCS is a self-administered scale consisting of 100 items. According to the author (Fitts, 1964) the scale can be administered to anyone with a sixth-grade reading level. The test can be completed in 10 to 20 minutes. Researchers have found the Tennessee Self-Concept Scale to be useful when studying self-concept (Short et al., 1984; Brinkmann \& Hoskins, 1979; Beekman et al., 1985; Collingwood \& Willett, 1971; Puglisi \& Jackson, 1978; Fitzgibbons \& Cutler, 1972; Vacchiano \& Strauss, 1968).

\section{Summary}

Self-concept is a primary factor in determining the individual's personality and level of adjustment. High levels of personality adjustment are associated with a positive self-concept (Gaber, 1984; Brinkmann \& Hoskins, 1979; Gergen, 1971; Schwarzer, 1984; Shavelson \& Marsh, 1984; Driever, 1976; Fitts, 1972).

Gergen (1971) defined a process in wich one develops self-concept. This process involves three stages. Sensation, cognition, and being reinforcement dependent are aspects of the self-concept devlopment theory. The Individual begins to increase his sensitivity to stimuli during the sensation stage and is able to perceive differences in the stimuli. During the cognitive stage, the person becomes capable of registering and grouping together the stimuli. The reinforcement dependent stage 
allows the individual to develop a new self-concept. A new self-concept will be formed if stimuli in his environment such as pain and punishment persist (Gergen, 1971). A similar definition of self-concept is used by Schwarzer (1984). He believes that "self-concept can be conceived of as the total of self-reverent information which an individual has processed, stored, and organized in a systematic manner" (Schwarzer, p. 1).

Shavelson and Marsh (1984) subdivide self-concept into three categories into three categories: 1) academic, 2) social and emotional, and 3) physical. Shavelson and Marsh (1984) believe that the academic category is the most important in developing one's own self-concept because of the evaluative feedback recelved from family and peers. This feedback is essential in forming the social and emotional and the physical categories of self-concept. Driever (1976) defines self-concept as "the composite of beliefs and feelings that one holds about oneself at a given time, formed from perceptions, particularly of other's reactions, and directing one's behavior" (Driever, p. 169). In another definition of self-concept, Gaber (1984) defines self-concept "as the way an individual sees himself" (Gaber, p. 207). Fitt's (1972) realized that a person's self-concept explains information about the person's feelings, attitudes and mental health. 
Research has shown that by the year 2030,20 to 30 percent of the United States population will be over the age of 65 (Lewis, 1984; Aitken, 1982). Taft (1985), Bloom (1961), Brody et al. (1971), Guptill (1969) and Preston and Gudiksen (1966) agree that older people are, as a group, looked upon as a risk for a lowered self-concept. This is because they suffer diminished work and social roles, and are vulnerable to grief, i.e., loss of family members and friends (Taft, 1985).

Denial is a common factor with the older adult (Aitken, 1982; Preston \& Gudikson, 1966). 0lder adults will deny physical illness by viewing themselves as being young. To them, physical illness occurs only in those who are old (Aitken, 1982).

Stroke is the leading cause of death in the United States (Dombovy et al., 1986). Most survivors are left with mental and physical disabilities (Dombovy et a1., 1986).

Stroke victims occasionally display a negative self-image. They believe that because of their disability, others will feel uneasy towards them. This uneasiness has adverse affects on the rehabilitation process. The stroke victim ueeds to accept their disability before participating in a rehabilitation program. Until the stroke victim learns to accept himself, maximum benefit from rehabilitation programs will not be obtained (Brinkmann \& Hoskins, 1979). 
Self-concept improves following exercise programs. Subject's appearance, and socialization techniques have been found to improve as they become more physically able and independent. Increases in physical fitness allow the subject to gain positive feedback which will improve their self-concept. Research indicates that self-concept is improved following an exercise program (Short et a1., 1984; Brinkmann \& Hoskins, 1979; Collingwood \& Willett, 1971). The literature reviewed indicates that increases in physical fitness result in positive changes in self-concept.

The original purpose of the Tennessee Self-Concept Scale "was to develop a research instrument that might contribute to the difficult criterion problem in mental hea1th research" (Fitts, p. 1).

Researchers have found the Tennessee Self-Concept Scale to be useful when studying self-concept (Short et al., 1984; Brinkmann \& Hoskins, 1979; Beekman et a1., 1985; Collingwood \& Willett, 1971; Puglisi \& Jackson, 1978; Fitzgibbons \& Butler, 1972; Vacchiano \& Strauss, 1968). 


\section{Chapter III}

\section{Procedures}

The purpose of this chapter is to describe the procedures which were used in conducting this study. Characteristics of the subjects participating in this study will be detailed along with the design and description of the self-concept test.

\section{Subjects}

The 29 experimental subjects selected for this study were individuals who had suffered from a stroke. The subjects' ages ranged from 45 to 75 years. The range of time from the onset of the stroke to the first day of Winter Quarter, 1990, for the experimental subjects, was from six months to 15 years. The experimental subjects had been enrolled in a De Anza College adapted physical education class ranging from their first quarter to 15 years.

These subjects were currently enrolled in an adapted physical education exercise class at De Anza College during the Winter Quarter, 1990. The subjects were disqualified if they were aphasic or intellectually impaired and so unable to answer written questions. This was determined by the medical form required for participation in adapted physical exercise classes at De Anza College signed by the subject's physician. This medical form is required by all students enrolled in adapted physical education classes at 
De Anza College. Random sampling techniques were not used since the post-stroke population at De Anza College who qualified for this study was fewer than 30 students.

The seven control subjects were chosen from the Reach Program at Foothill College. The subjects were enrolled in the Reach Program during the Winter Quarter, 1990. The subjects age ranged from 40 to 80 years. The range of time from the onset of the stroke for the control subjects to the first day of Winter Quarter, 1990, was from nine months to 9 years. The control subjects' enrollment in the Reach Program at Foothill College, during Winter Quarter, 1990, ranged from this being their first quarter to a maximum of two previous quarters.

Description of the Instrument

The Tennessee Self-Concept Scale (TSCS) by Fitts (1964) was used to measure the subject's self-concept. The TSCS was chosen because physicians and physical therapists have used this scale to measure self-concept changes in physical training programs; the scale is standardized, and can be self-administered in 10 to 20 minutes. Test-retest reliabilities range from .75 to .92 (Fitte, 1965). The TSCS has been demonstrated to possess construct validity (Vacchiano \& Strauss, 1968).

The TSCS consists of 100 self-descriptive statements to which subjects respond on a five-point Likert Scale. 
The Likert Scale ranges from (1) "completely true" to (5) "completely false" allowing students to respond to the degree to which that item applies to themselves.

\section{Research Design}

A two week pilot study was conducted during the month of December, 1989 using five randomly-selected wheelchair athletes. From the results of the pilot stuay, aiI test procedures were reviewed to ensure that the testing protocol used both before the administratation of the TSCS and after was efficient for the proposed study.

This study dealt with the assesment of self-concept using male and female post-stroke subjects. The subjects answered the Tennessee Self-Concept Scale (TSCS) before and after a twelve-week adapted physical education exercise class. The responses for the pre-test and post-test were evaluated in terms of whether self-concept increased, decreased, or stayed the same following a twelve-week adapted physical education exercise class at De Anza Coilege during Winter Quarter, 1990.

The protocol used for test administration began with filing a human subjects statement of assurance form with San Jose State University. The students completed a bumar consent form prior to initiation of the study. The site used for this completion was De Anza College. A packet containing the TSCS questionnaire was hand carried to the 
students. The packet included:

1. A cover letter outlining the importance of

completing the questionnaire emphasizing that the subject was participating in a master's thesis study.

2. A statement advising the students to complete the questionnaire alone.

3. General instructions regarding completion of the scale.

4. A statement assuring confidentiality.

5. The TSCS questionnaire.

6. A letter thanking the subjects for participating in the study.

7. A statement informing the subjects that the study results will be available upon completion of the thesis and upon request.

\section{Research Hypotheses}

The hypotheses for this study were tested at the .008 level of signiflcance.

1. There will be no difference between the pre-test self-concept rankings and the post-test self-concept rankings for post-stroke students enrolled in adapted physical education exercise classes at De Anza College.

2. There will be no difference between the pre-test self-concept rankings and the post-test self-concept rankings regarding the experimental group and the control 
group .

3. There will be no difference between the pre-test self-concept rankings and post-test self-concept rankings regarding the Physical Self dimension of the Tennessee Self-Concept Scale.

4. There will be no difference between the pre-test self-concept rankings and post-test self-concept rankings regarding the Moral-Ethical Self dimension of the Tennessee Self-Concept Scale.

5. There will be no difference between the pre-test self-concept rankings and post-test self-concept rankings regarding the Personal Self dimension of the Tennessee SelfConcept Scale.

6. There will be no difference between the pre-test self-concept rankings and post-test self-concept rankings regarding the Family Self dimension of the Tennessee SeliConcept Scale.

7. There will be no difference between the pre-test self-concept rankings and post-test self-concept rankings regarding the Social Self dimension of the Tennessee SelfConcept Scale.

8. There will be no difference between the pre-test self-concept rankings and post-test self-concept rankings regarding the Self-Criticism Score of the Tennessee SelfConcept Scale. 
9. There will be no difference between the pre-test self-concept rankings and post-test self-concept rankings regarding the Total Self Score of the Tennessee Self-Concept Scale.

\section{Statistical Procedures}

An analysis of variance (ANOVA) was used to analyze the experimental and control group with regards to the pre-test and post-test of the Tennessee Self-Concept Scale. The alpha level was set at .008.

Summary

The TSCS was administered during the Winter Quarter, 1990 , to 30 post-stroke experimental students enrolled in adapted physical education exercise classes at De Anza College and 7 post-stroke control students enrolled in the Reach Program at Foothill College. The subjects received a packet containing the TSCS during the last class meeting of the first week. The packet contained explicit instructions on completing the TSCS, a confidentiality statement, a letter thanking the subjects for the participation in the study, and a statement informing the subject that the results of the study would be available upon completion of the thesis and upon request.

The statistical procedure included an interpretation of the results and an anaiysis of their relationship to the hypotheses at the .008 level of significance. 
Chapter IV

Results

The purpose of this study was to measure the influence of adapted physical education exercise classes on the selfconcept of the post-stroke individual. In this chapter the results are presented and described. Data were analyzed using analysis of variance on the SPSS computer program at the San Jose State University Computer Center.

Results

An analysis of variance (ANOVA) was used to analyze the experimental and control group with regards to the pre-test and post-test of the Tennessee Self-Concept Scale. The alpha level was originally set at .05. However, since six ANOVAS were conducted, this alpha level was divided by six (number of AMOVAS) as recommended by Dunn (1961). This avoids an inflation of the alpha level due to multiple application of the ÂNOVA.

Several inypotheses were tested in this study. Each will be addressed separately with explanations regarding the experimental and control group and the pre-test and post-test.

Hypothesis 1 stated that there would be no difference between the pre-test self-concept rankings and the post-test self-concept rankings for post-stroke students enrolled in adapted physical education exercise classes at De Anza 
College. The null hypothesis was accepted since the $E$ score was .002 ( $\mathrm{p}>.008)$ (see Table 1 ).

Hypothesis 2 stated that there would be no difference between the pre-test self-concept rankings and the post-test self-concept rankings regarding the experimental group and the control group. The null hypothesis was accepted since the $\underline{F}$ score was $.002(\mathrm{p}>.008)$ (see Table 1).

Table 1

Analysis of Variance

Total Self Score by Test $(1,2)$ Group $(1,2)$

\begin{tabular}{lrrrrr}
\hline $\begin{array}{l}\text { Sources } \\
\text { of Variation }\end{array}$ & Sum of & & Mean & & \multicolumn{1}{l}{ Sig } \\
& Squars & DF & Square & F & of F \\
\hline Main Effects & .458 & 2 & .237 & .905 & .523 \\
Test & .437 & 1 & .436 & 1.440 & .383 \\
Group & .036 & 1 & .036 & .368 & .798 \\
2-Way Interaction & .084 & 1 & .084 & .571 & .526 \\
Test, Group & .004 & 1 & .004 & .571 & .526 \\
Explained & .557 & 3 & .176 & .667 & .565 \\
Residual & 10.512 & 68 & .134 & & \\
\hline
\end{tabular}


Hypothesis 3 stated that there would be no difference between the pre-test self-concept rankings and post-test self-concept rankings regarding the Physical Self dimension of the Tennessee Self-Concept Scale of the experimental and control group. The null hypothesis was accepted for the pre-test and post-test self-concept rankings since the $F$ score was $.566(\mathrm{p}>.008)$. The $\mathrm{null}$ hypothesis was accepted regarding the Physical Self dimension for the experimental and control group since the $\underline{E}$ score was $.129,(\underline{p}>.008)$ (see Table 2).

Table 2

Analysis of Variance

Physical Self by Test $(1,2)$ Group $(1,2)$

\begin{tabular}{lccccc}
\hline $\begin{array}{l}\text { Sources } \\
\text { of Variation }\end{array}$ & $\begin{array}{c}\text { Sum of } \\
\text { Squares }\end{array}$ & DF & Square & $F$ & of F \\
& & & & & Mean \\
Main Effects & .093 & 2 & .046 & .347 & .708 \\
Test & .076 & 1 & .076 & .566 & .454 \\
Group & .017 & 1 & .017 & .129 & .721 \\
2-Way Interactions & .111 & 1 & .111 & .830 & .365 \\
Test, Group & .111 & 1 & .111 & .830 & .365 \\
Explained & .203 & 3 & .068 & .508 & .678 \\
Residual & 9.068 & 68 & .133 & & \\
\hline Total & 9.271 & 71 & .131 & &
\end{tabular}


Hypothesis 4 stated that there would be no difference between the pre-test self-concept rankings and post-test self-concept rankings regarding the Moral-Ethical Self dimension of the Tennessee Self-Concept Scale of the experimental and control group. The null hypothesis was accepted for the pre-test and post-test self-concept rankings since the $\underline{F}$ score was .248 ( $p>.008)$. The null hypothesis was accepted regarding the Moral-Ethical Self dimension for the experimental and control group since the $\underline{F}$ score was $1.895,(\underline{p}>.008)$ ( see Table 3 ).

Table 3

Analysis of Variance

Moral-Ethical Self by Test $(1,2)$ Group $(1,2)$

\begin{tabular}{lccccc}
\hline Sources & Sum of & & Mean & & Sig \\
of Variation & Squares & DF & Square & $F$ & of F \\
& & & & & \\
\hline Main Effects & .192 & 2 & .096 & 1.072 & .348 \\
Test & .022 & 1 & .022 & .248 & .620 \\
Group & .170 & 1 & .170 & 1.895 & .173 \\
2-Way Interactions & .003 & 1 & .003 & .032 & .858 \\
Test, Group & .003 & 1 & .003 & .032 & .858 \\
Explained & .195 & 3 & .065 & .725 & .540 \\
Residual & 6.106 & 68 & .090 & & \\
\hline Total & & & & & \\
\hline
\end{tabular}


Hypothesis 5 stated that there would be no difference between the pre-test self-concept rankings and post-test self-concept rankings regarding the Personal Self dimension of the Tennessee Seli-Concept Scale of the experimental and the control group. The null hypothesis was accepted for the pre-test and post-test self-concept rankings since the E score was .819 ( $\mathrm{p}>.008)$. The null hypothesis was accepted regarding the Personal Self dimension for the experimental and control group since the $F$ score was .009 $(\underline{p}>.008)($ see Table 4$)$.

Table 4

Analysis of Variance

Personal Self by Test $(1,2)$ Group $(1,2)$

\begin{tabular}{lrrrrr}
\hline Sources & Sum of & & Mean & & Sig \\
of Variation & Squares & DF & Square & $F$ & of F \\
\hline Main Effects & .061 & 2 & .030 & .414 & .662 \\
Test & .060 & 1 & .060 & .819 & .369 \\
Group & .001 & 1 & .001 & .009 & .923 \\
2-Way Interactions & .107 & 1 & .107 & 1.457 & .232 \\
Test, Group & .107 & 1 & .107 & 1.457 & .232 \\
Explained & .168 & 3 & .056 & .762 & .519 \\
Residual & 4.997 & 68 & .073 & & \\
\hline
\end{tabular}

Total

$\begin{array}{lll}5.165 & 71 & .073\end{array}$


Hypothesis 6 stated that there would be no difference between the pre-test self-concept rankings and post-test self-concept rankings regarding the Family Self dimension of the Tennessee Self-Concept Scale of the experimental and control group. The null hypothesis was accepted for the pre-test and post-test rankings since the $\underline{F}$ score was $1.259(\mathrm{p}>.008)$. The null hypothesis was accepted regarding the Family Self dimension for the experimental and control group since the $\underline{F}$ score was .134 ( $\mathrm{p}>.008$ ) (see Table 5). Table 5 Analysis of Variance Family Self by Test $(1,2)$ Group $(1,2)$

\begin{tabular}{lrrrrr}
\hline Sources & Sum of & & Mean & & Sig \\
of Variation & Squares & DF & Square & F & of F \\
& & & & & \\
\hline Main Effects & .144 & 2 & .072 & .697 & .502 \\
Test & .130 & 1 & .130 & 1.259 & .502 \\
Group & .014 & 1 & .014 & .134 & .715 \\
2 Way Interactions & .012 & 1 & .012 & .112 & .739 \\
Test, Group & .012 & 1 & .012 & .112 & .739 \\
Explained & .156 & 3 & .052 & .502 & .682 \\
Residual & 7.046 & 68 & .104 & & \\
\hline Total & 7.202 & 71 & .101 & &
\end{tabular}


Hypothesis 7 stated that there will be no difference between the pre-test self-concept rankings and post-test self-concept rankings regarding the Social Self dimension of the Tennessee Self-Concept Scale of the experimental and control group. The null hypothesis was accepted for the pre-test and posi-test rankings since the $\underline{F}$ score was .329 ( $\mathrm{p}>.008)$. In addition, the null hypothesis was accepted regarding the Social Self dimension for the experimental and control group since the $E$ score was .002 $($ p $>.008)($ see Table 6$)$.

Table 6

Analysis of Variance

Social Self by Test $(1,2)$ Group $(1,2)$

\begin{tabular}{lccccc}
\hline $\begin{array}{l}\text { Sources } \\
\text { of Variation }\end{array}$ & $\begin{array}{c}\text { Sum of } \\
\text { Squares }\end{array}$ & DF & Square & F & of F \\
& & & & Mean \\
\hline Main Effects & .035 & 2 & .017 & .165 & .848 \\
Test & .034 & 1 & .034 & .329 & .568 \\
Group & .000 & 1 & .000 & .002 & .968 \\
2-Way Interaction & .049 & 1 & .049 & .469 & .496 \\
Test, Group & .049 & 1 & .049 & .469 & .496 \\
Explained & .084 & 3 & .028 & .266 & .849 \\
Residual & 7.119 & 68 & .105 & & \\
\hline Total & 7.203 & 71 & .101 & &
\end{tabular}


Hypothesis 8 stated that there would be no difference between the pre-test self-concept rankings and post-test self-concept rankings regarding the Self-Criticism Score of the Tennessee Self-Concept Scale of the experimental and control group. The null hypothesis was accepted for the pre-test and post-test rankings since the $\underline{F}$ score was 5.439 ( $p>.008)$. The null hypothesis was accepted regarding the Self-Criticism dimension for the experimental and control group since the $\underline{E}$ score was .040 ( $p>.008$ ) (see Table 7).

\section{Table 7}

Analysis of Variance

Self-Criticism by Test $(1,2)$ Group $(1,2)$

\begin{tabular}{lrrrrr}
\hline Sources & Sum of & & Mean & & Sig \\
of Variation & Squares & DF & Square & $F$ & of F \\
& & & & & \\
\hline Main Effects & 2.316 & 2 & 1.158 & 2.739 & .072 \\
Test & 2.299 & 1 & 2.299 & 5.439 & .023 \\
Group & .017 & 1 & .017 & .040 & .843 \\
2-Way Interaction & .223 & 1 & .223 & .528 & .470 \\
Test, Group & .223 & 1 & .223 & .528 & .470 \\
Explained & 2.539 & 3 & .846 & 2.002 & .122 \\
Residual & 28.740 & 68 & .423 & & \\
\hline Total & & & & &
\end{tabular}


Hypothesis 9 stated that there would be no difference between the pre-test self-concept rankings and the post-test self-concept rankings regarding the Total Self Score of the Tennessee Self-Concept Scale of the experimental and control group. The null hypothesis was accepted for the pre-test and post-test rankings since the $\underline{F}$ score was .002 ( $p>008$ ). The nul1 hypothesis was accepted regarding the Total Self dimension for the experimental and control group since the $\underline{E}$ score was .355 ( $\underline{p}>.008)$. (See Table 1, page 30 ).

\section{Discussion}

Based upon the results of this study, the statistical analysis showed there was no significant difference between the pre-test and the post-test of the experimental group and the pre-test and post-test of the control group. In addition, when the experimental and control group were compared to each other, the results of the study show there was no statistical difference between the experimental and control group.

Research has found that self-concept is a primary factor in determining the individual's personality and level of adjustment. High levels of personality adjustment are associated with a positive self-concept (Gaber, 1984; Brinkmann \& Hoskins, 1979; Gergen, 1971; Schwarzer, 1984; Shavelson \& Marsh, 1984; Driever, 1976; Fitts, 1972). Stroke victims tend to display a negative attitude about 
their self-worth and believe others will feel uneasy towards them, because of their disability.

Hyman (1971) studied 200 stroke patients participating in a stroke rehabilitation program. Hyman reported that feelings of loneliness and lack of dependable relatives and friends exerted negative effects on motivation. Lipsey, Robinson, Godfrey, Pearson, Rao and Price (1985) studied stroke patients for several years and found "between 30 percent and 60 percent of both acute and chronic stroke patients have clinically significant depressions" (Lipsey et a1., 1985, p. 59).

A stroke victim must often develop an improved selfconcept. In order to develop an improved self-concept, opportunities for positive attitude development and behavior changes will be needed. Stroke victims must accept themselves before they can obtain maximum benefit from a rehabilitation program. The results of this study revealed no significant difference between the pre-test and post-test scores on the Tennessee Self-Concept Scale for the experimental and control subjects. The absence of a significant difference in test scores may have been a result of the subjects not accepting themselves as stroke victims. This theory would support the current research findings, that stroke victims must first accept themselves before developing a new self-concept. 
In addition to the subjects not accepting cheir new identity, lack of statistical difference between the control and experimental group may have been because of the researcher's choice of the control group. The control group was not a pure or uninfluenced group regarding self-concept. The control group was involved in counseling sessions for twelve weeks. These sessions, attended by stroke victims only, were conducted as small group discussions by an instructor. The researcher chose this control group because they represented the largest sample size of stroke victims not involved in adapted physical education classes. The researcher's subjective experience with the poststroke population did not forecast the control group's improvement in their self-concept without the discipline of adapted physical education. The Foothill College Reach Program is designed to provide the essential link between outpatient rehabilitation and full communty reintegration. Perhaps the sense of belonging is enough to provide opportunity for positive attitude development and behavior changes needed to improve self-concept.

One other reason for the lack of statistical difference between the control and experimental group may have been the small group of subjects used in this study. The small number of subjects may have contributed to the low statistical power, which would make significant differences 
more difficult to determine.

Despite research that has shown improvements in selfconcept following exercise programs (Short et al., 1984; Brinkmann \& Hoskins, 1979; Col1ingwood \& Willet, 1971), this study did not conclude that self-concept is improved following exercise programs. However, seventeen subjects did improve self-concept. Thirteen experimental group subjects at De Anza Coliege and 4 control group subjects at the Reach Program at Foothill College improved their self-concept during the 1990 Winter Quarter.

A few of the subjects in this study were extremely verbal about the questions regarding the Tennessee SelfConcept Scale. Many of the subjects were familiar with these types of scales and tried to find the questions that would "void" another question. Before completing the post-test, one experimental subject suggested that the researcher switch his post-test for his pre-test so that the results of his tests would show an improvement in selfconcept. These subjects' test results, and the cumulative impact on the study, may have been skewed by these deviations in completing the questionnaire.

In some cases, subjects did not answer the questions they felt were appropriate such as questions on religion and how they treated their parents. They thought the questions on religton and behavior toward their parents to 
be a violation of their privacy. Three subjects refused to answer these questions on the pre-test and the post-test.

Other comments by experimental subjects were:

1. In addition to using the Tennessee Self-Concept

Scale for the study, the researcher should devise a questionnaire asking the students about life before the stroke such as job situation and family life. Included in this questionnaire should be questions regarding their life now such as are they involved in activities outside their home, or do they stay home and watch television all day. This questionnaire would allow the researcher to understand more about the subjects before and after their stroke.

2. Repeat the study using both male and female subjects and state gender as a limitation. Most of the male subjects, prior to their stroke, were employed. The stroke resulted in a forced early retirement. Most of the female subjects were not employed outside of the home before their stroke.

3. Repeat the study using only one subject. This subject should be someone who is one-year post-stroke (or less) and enrolled in adapted physical education at De Anza College for their first quarter. This would allow the researcher to analyze the subject during the period that they are establishing a new self-concept. 
One experimental subject commented, at the end of the 1990 Spring Quarter, that the reason he felt improvements in his self-concept was the assistant helping him perform the adapted physical education exercises. The subject felt the positive reiationship established with the assistant, helped him improve his self-concept. 


\author{
Chapter V \\ Summary, Conclusions, and Recommendations
}

Summary

The purpose of this study was to measure the influence of adapted physical education exercise classes on "an individual's perception of himself" (Brinkmann \& Hoskins, 1979, p. 859) using post-stroke subjects.

Twenty-nine post-stroke students enrolled in adapted physical education classes at De Anza College participated as the experimental group in this study. The control group consisted of seven post-stroke students enrolled in the Reach Program at Foothill College. The experimental group attended their adapted physical education classes during the Winter Quarter 1990 for twelve weeks. The control group attended a counseling class during the Winter Quarter 1990 for twelve weeks. Each group was administered the Tennessee Self-Concept Scaie (TSCS) before and after the twelve-week Winter Quarter 1990.

\title{
Conclusions
}

Based on the resuits of this study, the following conclusions were made:

1. Post-stroke students enrolled in adapted physical education classes at De Anza College, during the 1990 Winter Quarter for twelve weeks, showed no statistically significant improvement in self-concept using the Tennessee Self-Concept 
Scale as the inventory for measuring self-concept.

2. Post-stroke students enrolled in a counseling class througi the Reach program at Foothill College, during the 1990 Winter Quarter for twelve weeks, statistically revealed no statistically significant improvement in self-concept using the Tennessee Self-Concept Scale as the inventory for measuring self-concept.

3. The researcher found when comparing the improvement in self-concept of the experimental group with the control group, there was no significant difference $(p>.008)$ regarding self-concept using the Tennessee Self-Concept Scale as the inventory for measuring self-concept.

\section{Recommendations}

Further research should be conducted on post-stroke victims with regards to improvements in self-concept, after enrollment in adapted physical education programs.

The following recommendations are made for further research:

1. This study should be repeated using stroke victims enrolled in adapted physical education classes.

2. This study should be repeated using a random sampling of a larger group of male and female subjects in order to improve statistical power.

3. This study should be repeated using experimental subjects entering an exercise program after the onset 
of their physical disability.

4. If possible, this study should be repeated using control subjects who are not participating in any form of activity to increase their self-concept.

5. This study should be repeated comparing the measurable improvement in self-concept of the stroke victims, enrolled in adapted physical education, to stroke victims enrolled in counseling classes. This may facilitate determining the most desirable mix of adapted physical education and counseling, to optimize the stroke victim's rate of self-concept improvement.

6. This study should be repeated using the 1990 guidelines for developing and maintaining cardiorespiratory and muscular fitness established by the American College of Sports Medicine (April, 1990).

7. This study should be repeated comparing male poststroke subjects to female post-stroke subjects, to test gender as a primary variable regarding improvement in self-concept. 


\section{References}

Aitken, M.J. (1982). Self-concept and functional independence in the hospitalized elderly. The American Journal of Occupational Therapy. 36, 243-250.

American College of Sports Medicine. (1990). The recommended quantity and quality of exercise for developing and maintaining cardiorespiratory and muscular fitness in healthy adults. Medicine and Science in Sports and Exercise, 22, 265-273. Beekman, C.E., Axtel1, I., Noland, R., \& West, J. (1985). Self-concept: An outcome of a program for spina1 pain. Pain, 22, 59-66.

Beverley, E.V. (1975). Living happily with oneself-and with others. Geriatrics, 30, p. 129-142.

Bloom, R. (1961). Age and the self-concept. American Journal of Psychiatry, 118, 534-538.

Brinkmann, J.R., \& Hoskins, T. A. (1979). Physical conditioning and altered self-concept in rehabilitated hemiplegic patients. Physical Therapy, 54, 859-865. Brody, E.M., Kleban, M.H., Lawton, M.P., \& Silverman, H.A. (1971). Excess disabilitites of mentally impaired aged: Impact of individualized treatment. The Gerontologist, 1 , 124-132. 
Collingwood, T. R., \& Willett, L. (1971). The effects of physical training upon self-concept and body attitude. Journal of Clinical Psychology, 27, 411-412. Collingwood, T.R. (1972). The effects of physical training upon behavior and self attitudes. Journal of Clinical Psychiatry, 28, 583-585.

Dombovy, M.L., Burton, A., Sandrok, B., \& Basford, J. (1986). Rehabilitation for stroke: A review. Stroke, 17, 363-367.

Driever, M.J. (1976). Theory of self-concept, In Roy, S.C. (ed). Introduction to Nursing: An Adaptation Model, (pp. 169-179). Englewood Cliffs, N.J., Prentice-Hall, 1976.

Dunn, 0.J. (1961). Multiple comparisons among means. Journal of the American Statistical Association, 56, $52-64$.

Fitts, W.H. (1964). Manual, Tennessee Self-Concept Scale. Counselor Recordings and T'ests. Fitzgibbons, D.J. \& Cutler, R. (1972). The factor structure of the Tennessee Self-Concept Scale among lower-class urban psychiatric patients. Journal of Clinical Psychology, 28, 184-186.

Gaber, L.B. (1984). Structural dimensions in aged selfconcept: A Tennessee Self-Concept Study. British Journal of Psychology, 75, 207-212. 
Gergen, K., J. (1971). The Concept of Self. New York:

Holt, Rinehart, and Winston, Inc.

Guptil1, C.S. (1969). A measure of age identification.

Gerontologist, 9 , 96-102.

Heinzelmann, F., \& Bagley, R.W. (1970). Response to

physical activity programs and their effects on health

behavior. Public Health Reports, 85, 905-911.

Hyman, M.D. (1971). The stigma of stroke. Geriatrics, 26, 132-141.

Labi, M.L.C., Phillips, T.F., \& Gresham, G.E. (1980). Psycho-social disability in physically restored longterm stroke survivors. Archives of Physical Medicine and Rehabilitation, 61, 561-565.

Lewis, C.B. (1984). Rehabilitation of the oluer person: A psychosocial focus. Physical Therapy, 64, 517-522. Lipsey, J.R., Robinson, R.G., Pearson, G.D., Rao, K., \& Price, T.R. (1985). The dexamethasone suppression test and mood following stroke. American Journal of Psychiatry, 142, 318-323.

Lipsey, J.R., \& Robinson, R.G. (1987). Depression: a frequently untreated complication of stroke. Medical Aspects of Human Sexuality, 31, 57-65.

Marsh, M. (1984). A day rehabilitation stroke program. Archives of Physical Medicine and Rehabilitation, 65, 320-323. 
Morgan. W.P., Roberts, J.A., Brand, F. R. \& Feinerman, A.D. (1970). Psychological effect of chronic physical activity. Medicine and Science in Sport, 2, 213-217. Preston, C.E., \& Gudiksen, K.S. (1966). A measure of self-perception among older people. Journal of Gerontology, 21, 63-71.

Puglisi, J. T. \& Jackson, D.W. (1978). Age indentification and self-concept in later adulthood. Psychology Rep, 43, 789-790.

Robinson, R.G., Bolduc, P.L., Kubol, K.L., Starr, L.B., \& Price, T.R. (1985). Social functioning assessment in stroke patients. Archives of Physical Medicine and Rehabilitation, 66, 496-500.

Shavelson, R.J. \& Marsh, H.W. (1984). On the structure of self-concept. In R. Schwarzer (Ed.), Self-Related Cognitions in Anxiety and Motivation. (pp.16-23). Hillsda1e: Er1baum.

Schwarzer, R. (1984). The seif in anxiety, stress and depression. Amsterdam: Elsevier Science Publishers, 1984.

Short, M. A., DiCar1o, S., Steffee, W.P., \& Pavlou, R. (1984). Effects of physical conditioning on self-consept of adult obese males. Physical Therapy, 64, 194-198. Taft, L.B. (1985). Self-esteem in later 1ife: A nursing perspective. ANS, $\underline{8}, 77-84$. 
Tesser, A. \& Campbe11, J. (1983). Self-definition and self-evaluation maintenance. In J. Suls, and A.G. Greenwald, (Eds.). Psychological Perspectives on the Se1f. (pp. 1-31). London: Lawrence Erlbaum Associates. Thomas, C.L. (Ed.). (1981). Taber's Cyclopedic Medical Dictionary. (14th ed.). F.A. Davis Company: Philadelphia. Vacchiano, R.B., \& Strauss, P.S. (1968). The construct validity of the Tennessee Self-Concept Scale. Journal of C1inical Psychology, 24, 323-326. 
Appendix A 


\section{AGREEMENT TO PARTICIPATE IN RESEARCH SAN JOSE STATE UNIVERSITY}

\section{RESPONSIBLE INVESTIGATOR: Mary Bennett}

TITLE OF PROTOCOL: The influence of adapted physical education on the human behavior of the post-stroke student.

I have been asked to participate in a research study that is investigating the influence of adapted physical education on the human behavior of the post-stroke student. The results of this study should further our understanding of the post-stroke student with regards to human behavior.

I understand that:

1) I will be asked to to complete the Tennessee Self-Concept Scale before and after the 1990 twelve-week Wincer Quarter at De Anza College.

2) The results of this study may be published, but any information from this study that can be indentified with me will remain confidential and will be disclosed only with my permission.

3) There will be no benefits to me with regards to this study. However, I may suffer from psychological stress from filling out the scale and from participating in a graduate student's thesis.

4) Any questions about my participation in this study will be answered by Mary Bennett at (408) 732-0907. Complaints about the procedures may be presented to Dr. Greg Payne (advisor for Human Performance graduate students) at (408) 924-3028, or Dr. James Bryant (Department chair for Human Performance at (408) 924-3010. For questions or complaints about research subject's rights, or in the event of research-related injury, contact Serena Stanford, Ph.D. (Academic Vice President for Graduate Studies and Research) at (408) 924-2480. 
5) My consent is given voluntarily without being coerced; I may refuse to participate in this siudy or in any part of this study, and I may withdraw at any time, without prejudice to my relations with San Jose State University or De Anza College.

6) I have received a copy of this consent form for my file.

7) Subjects' names will be kept confidential and for the purposes of this study, numbers will be used in the place of subject's names.

8) Thesis committee members, Dr. Greg Payne, Dr. Shirley Reekie, and $\mathrm{Mr}$. James Haynes will have access regarding information about the study.

9) The results of this study and information regarding the study will be kept under lock and key at Mary Bennett's address.

I HAVE MADE A DECISION WHETHER OR NOT TO PARTICIPATE. MY SIGNATURE INDICATES THAT I HAVE READ THE INFORMATION PROVIDED ABOVE AND THAT I HAVE DECIDED TO PARTICIPATE. 


\section{AGREEMENT TO PARTICIPATE IN RESEARCH SAN JOSE STATE UNIVERSITY}

\section{RESPONSIBLE INVESTIGATOR: Mary Bennett}

TITLE OF PROTOCOL: The influence of adapted physical education on the human behavior of the post-stroke student.

I have been asked to participate in a research study that is investigating the influence of adapted physical education on the human behavior of the post-stroke student. The results of this study should further our understanding of the post-stroke student with regards to human behavior.

I understand that:

1) I will be asked to to complete the Tennessee Self-Concept Scale before and after a twelve-week session of the Foothill Stroke Program.

2) The results of this study may be published, but any information from this study that can be indentified with me will remain confidential and will be disclosed only with my permission.

3) There will be no benefits to me with regards to this study. However, I may suffer from psychological stress from filling out the scale and from participating in a graduate student's thesis.

4) Any questions about my participation in this study will be answered by Mary Bennett at (408) 732-0907. Complaints about the procedures may be presented to Dr. Greg Payne (advisor for Human Performance graduate students) at (408) 924-3028, or Dr. James Bryant (Department chair for Human Performance at (408) 924-3010. For questions or complaints about research subject's rights, or in the event of research-related injury, contact Serena Stanford, Ph.D. (Academic Vice President for Graduate Studies and Research) at (408) 924-2480. 
5) My consent is given voluntarily without being coerced; I may refuse to participate in this study or in any part of this study, and I may withdraw at any time, without prejudice to my relations with San Jose State University or Foothill College.

6) I have received a copy of this consent form for my file.

7) Subjects' names will be kept confidential and for the purposes of this study, numbers will be used in the place of subject's names.

8) Thesis committee members, Dr. Greg Payne, Dr. Shirley Reekie, and Mr. James Haynes will have access regarding information about the study.

9) The results of this study and information regarding the study will be kept under lock and key at Mary Bennett's address.

I HAVE MADE A DECISION WHETHER OR NOT TO PARTICIPATE. MY SIGNATURE INDICATES THAT I HAVE READ THE INFORMATION PROVIDED ABOVE AND THAT I HAVE DECIDED TO PARTICIPATE. 
Dear Subject:

Thank you for agreeing to complete this questionnaire which is part of my master's thesis. This questionnaire will determine the influence of adapted physical education classes on the human behavior of the post-stroke student.

I cannot stress the importance of returning this material on time and as soon as possible. Because this is part of a master's thesis, a very strict time schedule must be adhered to.

Please read all the information and instructions before completing the Tennessee Self-Concept Scale. If you have any questions regarding the study, please do not hesitate to call me at (408) 732-0907.

If you would like to see the results of this study regarding self-concept, please contact me at the above number and $I$ will be happy to share the results with you.

Thank you,

Mary Bennet: 
PLEASE NOTE

Copyrighted aterials in this document have not been filmed at the request of the author. They are available for consultation, however, in the author's university library.

59-65

University Microfilms International 